\title{
Impact of the Level of Urothelial Carcinoma Involvement of the Prostate on Survival after Radical Cystectomy
}

\author{
Marco Moschini $^{\mathrm{a}, \mathrm{b}}$, Francesco Soria ${ }^{\mathrm{a}, \mathrm{c}}$, Martin Susani ${ }^{\mathrm{d}}$, Stephan Korn ${ }^{\mathrm{a}}$, Alberto Briganti ${ }^{\mathrm{b}}$, \\ Morgan Roupret ${ }^{\mathrm{e}}$, Christian Seitz ${ }^{\mathrm{a}}$, Killian Gust ${ }^{\mathrm{a}}$, Andrea Haitel ${ }^{\mathrm{d}}$, Francesco Montorsi ${ }^{\mathrm{b}}$, \\ Gregory Wirth $^{\mathrm{a}, \mathrm{f}}$, Brian D. Robinson ${ }^{\mathrm{g}}$, Pierre I. Karakiewicz ${ }^{\mathrm{h}}$, Mehmet Özsoy ${ }^{\mathrm{a}}$, Michael Rink $^{\mathrm{i}}$ \\ and Shahrokh F. Shariat ${ }^{\mathrm{a}, \mathrm{j}, \mathrm{k}, *}$ \\ ${ }^{a}$ Department of Urology, Comprehensive Cancer Center, Medical University of Vienna, Vienna General Hospital, \\ Vienna, Austria \\ ${ }^{\mathrm{b}}$ Department of Urology, Urological Research Institute, Vita-Salute University, San Raffaele Scientific Institute, \\ Milan, Italy \\ ${ }^{\mathrm{c}}$ Department of Surgical Sciences, Division of Urology, San Giovanni Battista Hospital, University of Studies of \\ Torino, Torino, Italy \\ ${ }^{\mathrm{d}}$ Clinical Institute of Pathology, Medical University of Vienna, Vienna General Hospital, Vienna, Austria \\ ${ }^{\mathrm{e}}$ Department of Urology, Pitié-Salpêtrière Academic Hospital, Assistance Publique-Hôpitaux de Paris, Pierre \\ and Marie Curie Medical School, Paris 6 University, Paris, France \\ ${ }^{\mathrm{f}}$ Department of Surgery, Division of Urology, Geneva University Hospital, Geneva, Switzerland \\ ${ }^{\mathrm{g}}$ Department of Pathology, Weill Cornell Medical College, New York, NY, USA \\ ${ }^{\mathrm{h}}$ Cancer Prognostics and Health Outcomes Unit, University of Montreal Health Centre, Montreal, QC, Canada \\ ${ }^{i}$ Division of Urology, University Medical Center Hamburg-Eppendorf, Hamburg, Germany \\ ${ }^{\mathrm{j}}$ Department of Urology, Weill Cornell Medical College, New York-Presbyterian Hospital, New York, NY, USA \\ ${ }^{\mathrm{k}}$ Department of Urology, University of Texas Southwestern Medical Center, Dallas, TX, USA
}

\begin{abstract}
.
Objective: Urothelial prostatic involvement (UPI) at the time of radical cystoprostatectomy (RCP) was found associated with worse survival outcomes by several previous reports. Our aim is to evaluate the impact of different levels of UPI on survival outcomes using a large series of male patients treated with RCP.

Methods: Whole step section specimens from 995 male BCa patients were assessed for UPI defined as: no involvement vs. prostatic urethral carcinoma in situ (CIS) vs. lamina propria involvement vs. ductal CIS vs. prostate stromal involvement. Primary end point of the study was predictors of prostatic involvement at RCP and its impact on overall survival after surgery. Results: Prostatic involvement was recorded in 307 (30.9\%) patients: 28\% with prostatic urethral CIS, 12\% with lamina propria involvement, $13 \%$ with ductal CIS and $47 \%$ with stromal involvement. Median follow-up was 70 months. Patients with stromal involvement had a worse 5-year survival (12\%) than those with prostatic urethra CIS (40\%), lamina propria involvement $(36 \%)$, and ductal CIS $(35 \%)$. Considering predictors of prostatic involvement, multifocal tumor (Odds Ratio [OR]: $6.60, p<0.001)$, lymphovascular invasion (OR: $2.61, p<0.001)$, lymph node metastases (OR: $2.02, p<0.001)$ and CIS (OR: $2.02, p<0.001)$ were found associated. Similar predictors were found assessing stromal involvement.
\end{abstract}

\footnotetext{
*Correspondence to: Shahrokh F. Shariat, Department of Urology, Comprehensive Cancer Center, Medical University of Vienna,
}

Vienna General Hospital, Vienna, Austria. Tel.: +43 140400 26150; Fax: +43 140400 23320; E-mail: sfshariat@ gmail.com. 
Conclusions: Approximately one third of RCP patients harbor prostatic involvement of urothelial carcinoma. While all UPI are associated with worse overall survival, stromal involvement confers the worst outcome supporting its classification as T4 in the TNM staging.

Keywords: Bladder cancer, radical cystectomy, incidental, prostate cancer invasion

\section{INTRODUCTION}

Radical cystoprostatectomy with bilateral pelvic lymph node dissection (PLND) is the standard treatment for male patients harboring muscle invasive or very high-risk non-muscle invasive bladder cancer $[1,2]$. With the aim to improve sexual and functional outcomes, several prostate-sparing cystectomy techniques have been proposed [3-6]. However, the high incidence and potentially poor prognosis of urothelial carcinoma involvement of the prostate (UPI) makes these approaches too risky for widespread use [7-10].

Several authors reported incidence and survival implications of patients affected by UPI treated with radical cystoprostatectomy [7, 8, 11-14]. Depth of tumor involvement was significantly associated with survival outcomes [8], although this was evident only with prostatic stromal invasion [7]. Other studies failed to observe a survival impairment for patients with UPI where they showed similar survival of patients affected by pT3 disease [12].

However, only a minority of studies investigated the differential impact of different levels of UPI [7, 8]. To address these unknowns, we assessed the association of UPI with pathologic characteristics and survival outcomes in patients treated with radical cystoprostatectomy in a multicentric study composed by three referral centers.

\section{METHODS}

Data from 995 male patients treated with radical cystoprostatectomy for non-metastatic bladder cancer between 1983 and 2006 at three referral centers were included in the study. Patients were staged preoperatively with pelvic/abdominal computerized tomography or magnetic resonance and chest $\mathrm{x}$-ray. Each ethical committee approved the study. No patient was treated with neoadjuvant chemotherapy. Cystoprostatectomy specimens were analyzed by dedicated uropathologists. Prostatic urothelial carcinoma was stratified in four groups: prostatic urethral carcinoma in situ [CIS], lamina propria invasion, ductal CIS and prostatic stromal invasion. After the operation, the prostate was covered with India ink and after fixation for 24 hours in $4 \%$ neutral buffered formalin; the prostate specimens underwent step sectioning at $4 \mathrm{~mm}$ intervals. The apex, base and seminal vesicles were removed from each specimen and submitted in total for routine histological examination. Lymphovascular invasion was defined as the unequivocal presence of tumor cells within an endothelium-lined space without underlying muscular walls [15]. Focality of the tumor was visually evaluated and multifocality was defined as the presence of multiple papillary disease. Bladder neck involvement was visually determined. Positive soft tissue surgical margin was defined as the presence of tumor at inked areas of soft tissue on the radical cystoprostatectomy specimen. Adjuvant chemotherapy was administered on the bases of clinical and pathologic characteristics and physicians' preferences. History of concomitant CIS was defined as CIS diagnoses at any time before radical cystoprostatectomy. Variant histology was defined as the presence of histological variants different from urothelial carcinoma. History of CIS was defined as a previously CIS diagnosed at transurethral resection before radical cystoprostatectomy. Bladder neck involvement and focality were referred to the previous TUR before radical cystoprostatectomy. Given the initial agreement between the participating institutions, center identifiers were removed from the database.

Postoperative follow up was not standardized due to the retrospective nature of the study. However, patients were generally evaluated postoperatively every 3-4 months for the first year, semiannually for the second year, and annually thereafter. Examinations included radiological imaging with urographic phase (physical examination, laboratory testing, urine cytology, urethral washings in selected cases and bone scans when indicated. The institutional review board of each center approved this retrospective study.

\section{Covariates and end points}

All patients included in this study had complete clinical and pathological data. The primary end point was to assess predictors of UPI and stromal prostatic 
involvement at the time of radical cystoprostatectomy. Our second end point was to assess the association of the levels of prostatic involvement with other pathological features and overall survival. Vital status was identified from chart review and death certificates. On death certificates, bladder cancer was considered the cause of death when it was mentioned as the first cause on the list [16].

\section{Statistical analyses}

Descriptive statistics of categorical variables focused on frequencies and proportions. Means, medians, and Interquartile ranges (IQR) were reported for continuously coded variables. Chisquare and Mann- Whitney tests were used to compare the statistical significance of differences in proportions and medians, respectively. Univariable and multivariable logistic regression analyses were built to assess the impact of preoperative parameters on the prediction of prostatic involvement. Specifically, two models were presented: one with all the available confounders and one with only preoperative variables. Kaplan-Meier curve to estimate overall mortality-free rates was built stratifying according to the level of prostatic involvement. Univariable and multivariable Cox regression analyses tested the impact of UPI on overall mortality after accounting for all available confounders. Statistical analyses were performed using the $\mathrm{R}$ statistical package (R Foundation for Statistical Computing, Vienna, Austria) and SPSS v. 20.0 (IBM Corp., Armonk, NY, USA). All tests are two-sided and $p<0.05$ was considered as significant.

\section{RESULTS}

\section{Patient characteristics}

Clinical and pathologic demographics of the cohort are reported in Table 1. Median age was 69 years. Prostatic involvement was recorded in 307 (30.9\%) patients: $86(28.0 \%)$ recorded prostatic urethral CIS, $37(12.1 \%)$ prostatic ductal CIS, $40(13.0 \%)$ lamina propria invasion and $144(46.9 \%)$ prostatic stromal invasion. Considering pathologic $\mathrm{T}$ stage, T3 disease was found in 1 out 3 patients $(n=314,31.6 \%)$ while $300(30.2 \%), 214(21.5 \%)$ and $167(16.8 \%)$ were diagnosed with pT0-1, pT2 and pT4 a,b diseases, respectively. Moreover, UPI was associated win an increased risk of harboring lymph node metastases $(p<0.001)$. Patients diagnosed with prostatic stromal invasion were more like to harbor lymph node metastasis and LVI than those with other type of prostatic invasion, who turn, harbored a higher rate than patients without prostatic involvement. Conversely, concomitant CIS and multifocality at diagnosis was more frequent in patients with level without stromal prostatic disease compared to those with stromal prostatic invasion who harbored these features more commonly than patients without prostatic involvement. There was no difference in the rate of bladder neck involvement or variant histology between the different levels of prostatic involvement. Figure 1a-d are representative images of $\mathrm{BCa}$ invading the prostate.

\section{Predictors of prostatic involvement}

Univariable and multivariable logistic regression analyses predicting UPI and stromal involvement are depicted in Tables 2 and 3, respectively. At multivariable analyses, prostatic involvement was associated to multifocal tumor (OR: 6.60, $p<0.001$ ), lymphovascular invasion (OR: $2.61, p<0.001)$, lymph node metastases (OR: 2.02, $p<0.001$ ), concomitant CIS (OR: 2.02, $p<0.001)$. In the preoperative model, only age (OR: $1.02, p<0.05)$, multifocal tumor (OR: $6.91, p<0.001)$ and concomitant CIS (OR: 1.73, $p<0.001)$ were associated with an increased risk to harbor UPI at radical cystoprostatectomy. The same models were built predicting prostatic stromal involvement (Table 3). At multivariable analyses, prostatic prostatic stromal involvement was associated to age (OR: $1.03, p<0.05$ ), multifocal tumor (OR: 3.12, $p<0.001$ ), lymphovascular invasion (OR: $4.92, p<0.001)$ and lymph node metastases (OR: $2.81, p<0.001)$. However, when only preoperative parameters were considered only age (OR: 1.02, $p<0.05$ ) and multifocal tumor (OR: $3.81, p<0.001$ ) were associated with an increased risk to harbor prostatic stromal involvement involvement at radical cystoprostatectomy.

\section{Survival estimates according to level of prostatic involvement}

Mean and median follow-up were 82 and 70 months, respectively. Overall, 3, 5 and 10-year overall mortality-free rates were $62 \%, 53 \%$ and $29 \%$, respectively (Fig. 2A). Patients were subsequently stratified according to the level of prostatic involvement (Fig. 2B, $p<0.001$ ). Table 4 depicted univariable 
Table 1

Descriptive characteristics for the cohort of 995 male patients with non-metastatic bladder cancer who underwent radical cystoprostatectomy stratified according level of urothelial prostatic invasion

\begin{tabular}{|c|c|c|c|c|c|c|c|}
\hline Variables & $\begin{array}{l}\text { Entire Cohort } \\
\quad(n=995)\end{array}$ & $\begin{array}{c}\text { No invasion } \\
(n=688,69.1 \%)\end{array}$ & $\begin{array}{c}\text { prostatic } \\
\text { urethral CIS } \\
(n=86,8.6 \%)\end{array}$ & $\begin{array}{c}\text { prostatic } \\
\text { ductal CIS } \\
(n=37,3.7 \%)\end{array}$ & $\begin{array}{c}\text { lamina propria } \\
\text { invasion } \\
(n=40,4.0 \%)\end{array}$ & $\begin{array}{c}\text { prostatic stromal } \\
\text { invasion } \\
(n=144,14.5 \%)\end{array}$ & $p$ value \\
\hline \multicolumn{8}{|l|}{ Age at $R C P$, years } \\
\hline Mean & 67 & 67 & 66 & 69 & 70 & 69.2 & 0.1 \\
\hline Median (IQR) & $69(61-75)$ & $69(60-74)$ & $65(58-76)$ & $69(65-74)$ & $71(62-75)$ & $70(62-77)$ & \\
\hline \multicolumn{8}{|l|}{ Focality at TUR } \\
\hline Unifocal & $637(64.0 \%)$ & $515(74.9 \%)$ & $34(39.5 \%)$ & $14(37.8 \%)$ & $14(35.0 \%)$ & $60(41.7 \%)$ & $<0.001$ \\
\hline Multifocal & $278(27.9 \%)$ & $104(15.1 \%)$ & $49(57.0 \%)$ & $21(56.8 \%)$ & $25(62.5 \%)$ & $79(54.9 \%)$ & \\
\hline \multicolumn{7}{|l|}{ Histological types } & 0.4 \\
\hline Urothelial pure & $822(82.6 \%)$ & $554(80.5 \%)$ & $82(95.3 \%)$ & $32(86.5 \%)$ & $35(87.5 \%)$ & $119(82.6 \%)$ & 0.1 \\
\hline Variant & $98(9.8 \%)$ & $65(9.4 \%)$ & $3(3.5 \%)$ & $3(8.1 \%)$ & $5(12.5 \%)$ & $22(15.3 \%)$ & \\
\hline \multicolumn{8}{|l|}{ Grading } \\
\hline G1-G2 & $12(1.2 \%)$ & $12(1.7 \%)$ & - & - & - & - & 0.2 \\
\hline G3 & $908(91.3 \%)$ & $607(88.2 \%)$ & $85(98.8 \%)$ & $35(94.6 \%)$ & $40(100 \%)$ & $141(97.9 \%)$ & \\
\hline History of Concomitant CIS & $422(42.4 \%)$ & $251(36.5 \%)$ & $53(61.6 \%)$ & $21(56.8 \%)$ & $25(62.5 \%)$ & $72(50.0 \%)$ & $<0.001$ \\
\hline Positive STSM & $59(5.9 \%)$ & $42(6.1 \%)$ & $6(7.0 \%)$ & $3(8.1 \%)$ & $1(2.5 \%)$ & $7(4.9 \%)$ & 0.8 \\
\hline Adjuvant chemotherapy & $177(17.8 \%)$ & $111(16.1 \%)$ & $19(22.1 \%)$ & $11(29.7 \%)$ & $10(25.0 \%)$ & $26(18.1 \%)$ & 0.1 \\
\hline LVI & $386(38.8 \%)$ & $198(28.8 \%)$ & $41(47.7 \%)$ & $14(37.8 \%)$ & $16(40.0 \%)$ & $117(81.3 \%)$ & $<0.001$ \\
\hline LNI & $249(25.0 \%)$ & $114(16.6 \%)$ & $25(29.1 \%)$ & $11(29.7 \%)$ & $10(25.0 \%)$ & $89(61.8 \%)$ & $<0.001$ \\
\hline
\end{tabular}

RCP: radical cystoprostatectomy, IQR: interquartile range, CIS: carcinoma in situ, STSM: soft tissue surgical margin, LVI: lymphovascular invasion, LNI: lymph node invasion.

and multivariable Cox regression analyses assessing overall mortality in radical cystoprostatectomy patients. At multivariable analyses prostatic urethral CIS (Hazard Ratio [HR]: 1.53, confidence interval [CI]: $1.09-2.16, p=0.01$ ), prostatic ductal CIS (HR: 1.66, CI: $1.06-2.60, p=0.03$ ), lamina propria invasion (HR: 1.82, CI: 1.80-2.81, $p=0.007$ ) and prostatic stromal invasion (HR: 1.96, CI: 1.49-2.59, $p<0.001)$ UPIs were all associated with worse overall mortality when compared with no prostatic involvement.

\section{DISCUSSION}

In the present study, we evaluated the prognostic impact of the different levels of UPI in patients affected by bladder cancer and treated with radical cystoprostatectomy. We found that the type of involvement was associated with different survival expectations; stromal involvement was associated with the worse outcomes. These findings were confirmed at multivariable analyses after adjusting for all available confounders. All the type of UPI was associated with worse survival outcomes and increased risk of harboring node metastases. Moreover, we assessed predictors of UPI involvement. We found that multifocal bladder cancer, lymphovascular invasion, presence of lymph node metastases and the presence of concomitant CIS are all associated with a higher probability to incur in UPI at the time of radical cystoprostatectomy. Conversely we found that age, histological type and bladder neck involvement were all not associated with a differential risk of harboring UPI.

Our findings confirm previous literature assessing the impact of UPI on survival outcomes in radical cystoprostatectomy patients [7, 8, 11-14]. Knoedler et al. [8] reported data of 201 patients treated at a single center between 1980 and 2006 who harbored UPI. Similarly to our findings, depth of UPI was significantly associated with survival. Bruins et al. [17] analyzed prostatic involvement of 1,476 patients treated with radical cystoprostatectomy between 1971 and 2008. Stromal prostatic urothelial involvement was found in 163 patients $(11.0 \%)$, while 149 patients $(10.1 \%)$ had ductal involvement. On survival analyses, stromal involvement was a predictor of poor outcomes when compared to ductal involvement or no prostatic involvement.

Previous investigators assessed incidence and impact on survival of incidental prostate involvement in bladder cancer patients treated with radical cystoprostatectomy [17-22]. Specifically, incidental diagnosis of adenocarcinoma of the prostate was already described as not significant in predicting survival in bladder cancer patients treated with radical cystoprostatectomy and were therefore not included 


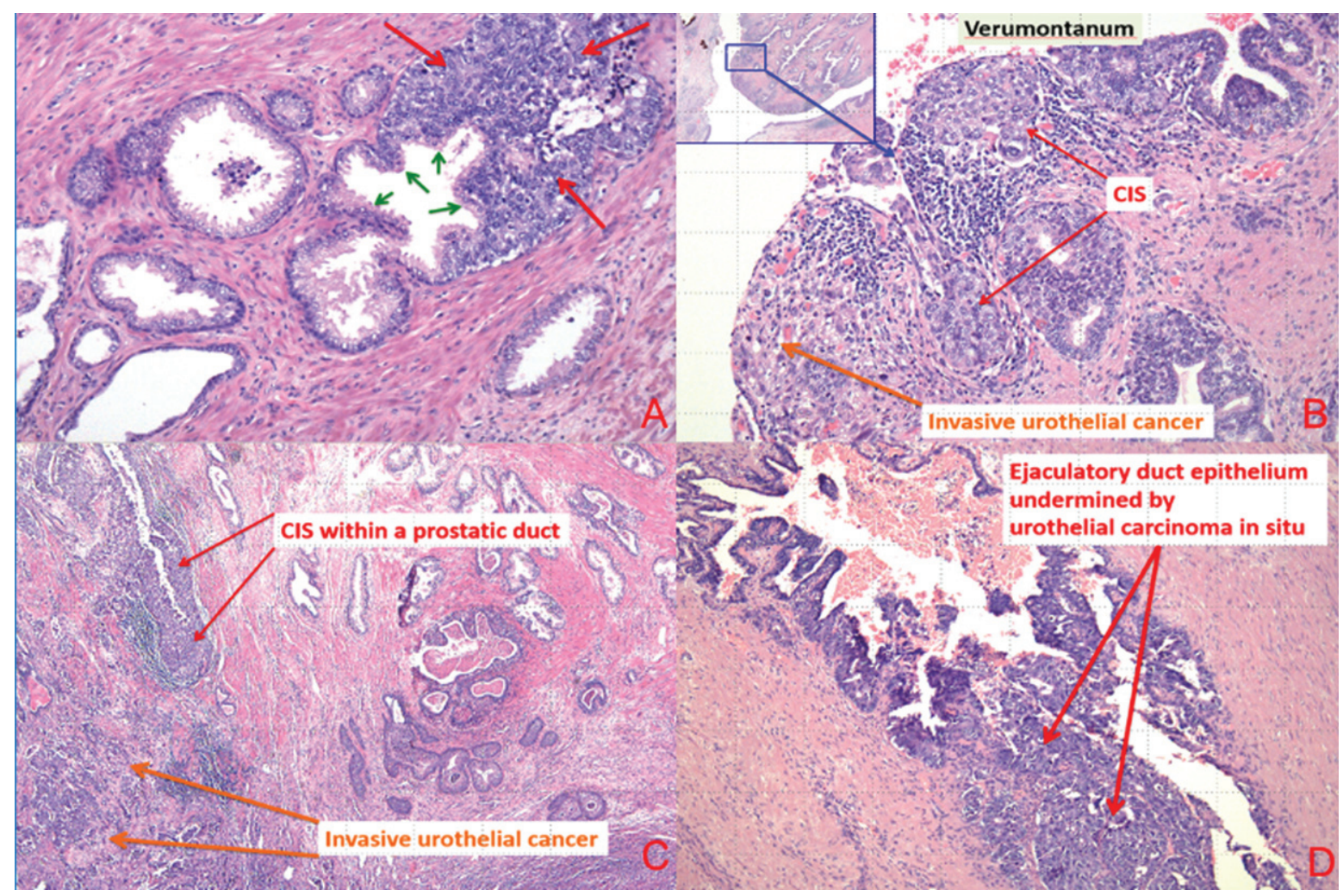

Fig. 1. (a) Carcinoma in situ urothelial cells invading prostatic glands (small green arrows represent secretory cell and large red arrows represent urothelial carcinoma in situ). (b) Urothelial carcinoma in situ prostatic urethra and ducts and invasive urothelial carcinoma at the level of verumontanum. (c) Urothelial CIS involving prostatic duct and invasive urothelial carcinoma. (d) Urothelial carcinoma in situ involving ejaculatory duct.

Table 2

Univariable and multivariable logistic regression analyses for prediction of prostatic involvement in 995 male patients treated with radical cystoprostatectomy for bladder cancer

\begin{tabular}{|c|c|c|c|c|c|c|}
\hline \multirow[t]{2}{*}{ Variables } & \multicolumn{2}{|c|}{ Univariable analyses } & \multicolumn{2}{|c|}{ Multivariable analyses } & \multicolumn{2}{|c|}{$\begin{array}{l}\text { Multivariable analyses, } \\
\text { preoperative model }\end{array}$} \\
\hline & OR (CI 95\%) & $p$ value & OR (CI 95\%) & $p$ value & OR (CI 95\%) & $p$ value \\
\hline Age, years & $1.01(1.00-1.03)$ & 0.04 & $1.01(1.00-1.03)$ & 0.07 & $1.02(1.01-1.03)$ & 0.04 \\
\hline \multicolumn{7}{|l|}{ Histological types } \\
\hline Urothelial pure & Ref & Ref & Ref & Ref & & \\
\hline Variant & $1.05(0.67-1.63)$ & 0.8 & $1.01(0.60-1.71)$ & 0.9 & & \\
\hline Multifocal vs. unifocal tumor at TUR & $7.06(5.16-9.66)$ & $<0.001$ & $6.60(4.71-9.25)$ & $<0.001$ & $6.91(5.03-9.49)$ & $<0.001$ \\
\hline Lymphovascular invasion & $3.36(2.53-4.47)$ & $<0.001$ & $2.61(1.76-3.85)$ & $<0.001$ & & \\
\hline Lymph node invasion & $3.95(2.92-5.34)$ & $<0.001$ & $2.02(1.45-3.31)$ & $<0.001$ & & \\
\hline History of Concomitant Carcinoma in situ & $1.93(1.46-2.55)$ & $<0.001$ & $2.02(1.45-2.82)$ & $<0.001$ & $1.73(1.27-2.36)$ & 0.001 \\
\hline Bladder neck involvement at TUR & $2.12(0.79-5.71)$ & 0.1 & $2.67(0.80-8.86)$ & 0.1 & $1.85(0.59-5.79)$ & 0.3 \\
\hline
\end{tabular}

in this study [23, 24]. Other studies assessed the impact of urothelial prostatic involvement on survival.

Although the presence of a concomitant incidental adenocarcinoma of the prostate, both indolent and aggressive, has been described as non-significant in the prediction of survival of patients treated for bladder cancer by several previous authors [23, 24], urothelial prostatic involvement at the time of radical cystoprostatectomy is one of the worst prognostic features in bladder cancer patients [17-19]. Other reports previously assessed factor associated with this poor pathological features $[25,26]$. Specifically, previous recurrence pattern, number of lesions and location of tumor were found as reliable predictors to the possibility to incur in UPI [25]. However, in comparison to 
Table 3

Univariable and multivariable logistic regression analyses for prediction of prostatic stromal invasion in 995 male patients treated with radical cystoprostatectomy for bladder cancer

\begin{tabular}{|c|c|c|c|c|c|c|}
\hline \multirow[t]{2}{*}{ Variables } & \multicolumn{2}{|c|}{ Univariable analyses } & \multicolumn{2}{|c|}{ Multivariable analyses } & \multicolumn{2}{|c|}{$\begin{array}{l}\text { Multivariable analyses, } \\
\text { preoperative model }\end{array}$} \\
\hline & OR (CI 95\%) & $p$ value & OR (CI 95\%) & $p$ value & OR (CI 95\%) & $p$ value \\
\hline Age, years & $1.02(1.01-1.03)$ & 0.03 & $1.03(1.01-1.04)$ & 0.04 & $1.02(1.01-1.03)$ & 0.04 \\
\hline \multicolumn{7}{|l|}{ Histological types } \\
\hline Urothelial pure & Ref & Ref & Ref & Ref & & \\
\hline Variant & $1.71(1.02-2.86)$ & 0.04 & $1.68(0.94-3.01)$ & 0.08 & & \\
\hline Multifocal vs. unifocal tumor at TUR & $3.82(2.63-5.54)$ & $<0.001$ & $3.12(2.06-4.72)$ & $<0.001$ & $3.81(2.61-5.55)$ & $<0.001$ \\
\hline Lymphovascular invasion & $8.26(5.30-12.88)$ & $<0.001$ & $4.92(2.85-8.49)$ & $<0.001$ & & \\
\hline Lymph node invasion & $6.99(4.79-10.19)$ & $<0.001$ & $2.81(1.76-4.49)$ & $<0.001$ & & \\
\hline History of Concomitant Carcinoma in situ & $1.28(0.89-1.83)$ & 0.2 & $1.30(0.86-1.97)$ & 0.2 & $1.11(0.76-1.61)$ & 0.6 \\
\hline Bladder neck involvement at TUR & $1.29(0.36-4.60)$ & 0.7 & $1.71(0.38-7.60)$ & 0.5 & $1.04(0.28-3.89)$ & 0.9 \\
\hline
\end{tabular}

previous reports, our study stratified prostatic urothelial involvement to different categories. We assessed the importance of each level of UPI with survival outcomes differing according the level of involvement which we demonstrated associated with different survival expectations.

Our study has therefore several clinical implications. First and foremost, our findings confirmed that a sub-stratification in urothelial prostatic involvement is needed as they have a differential effect on survival. Uro-pathologists should therefore consider this parameter in their evaluation of the prostatic spec- imen in radical cystoprostatectomy in the report. Despite our report is only a preliminary study, we think that a careful pathological description of the prostatic involvement should be recommended. Second, we found that several clinical and pathological factors should be considered by physicians to predict urothelial prostatic involvement. Third, we found that stromal involvement is strongly associated with worse survival outcomes in radical cystoprostatectomy patients. Moreover, we found that all the type of UPI was associated with worse survival outcomes even after accounting for all available confounders.
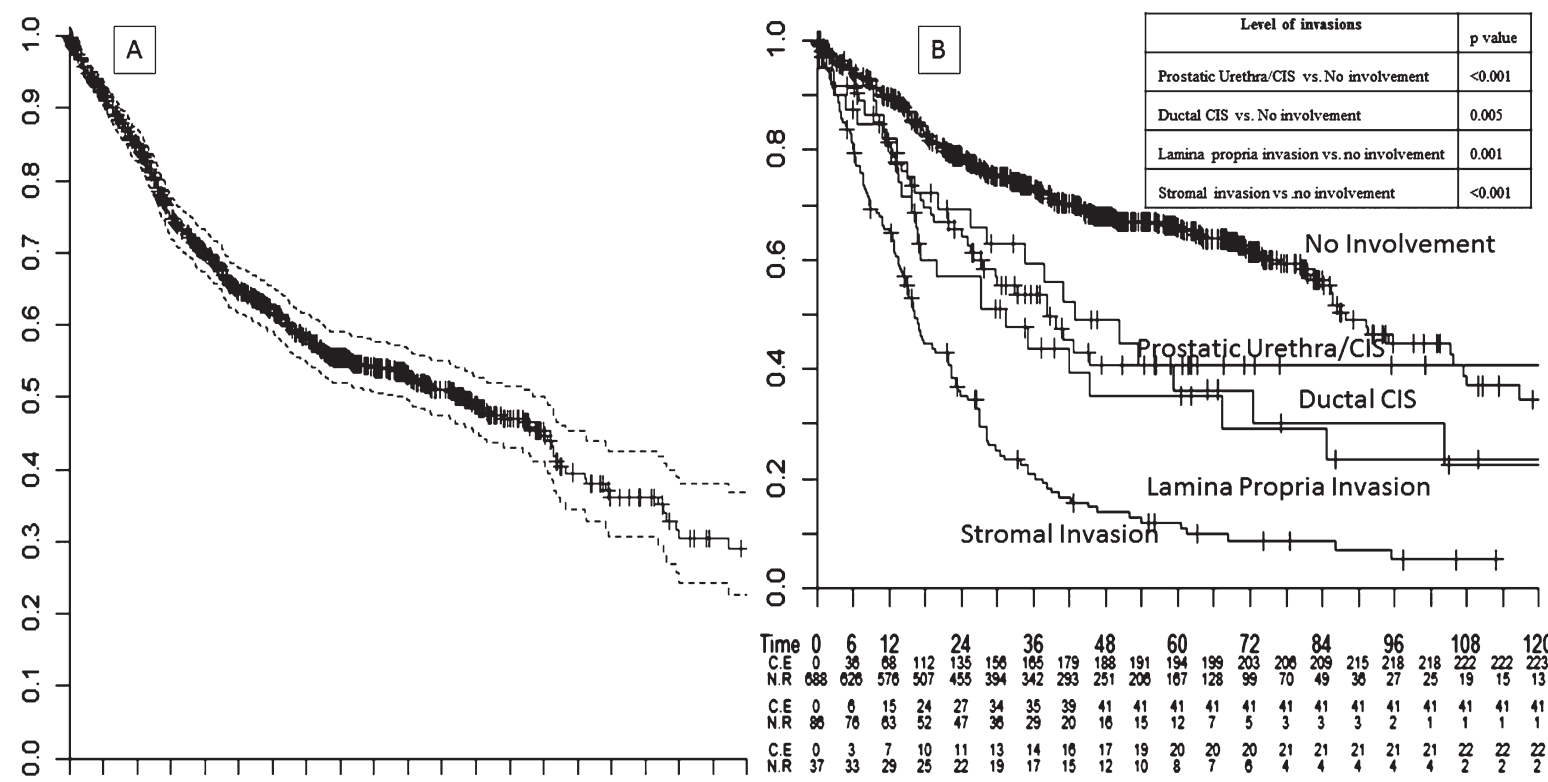

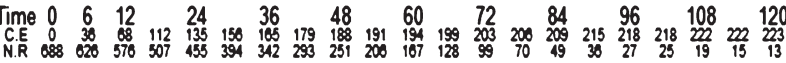

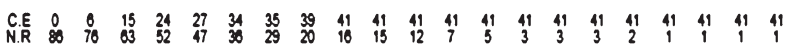
$\begin{array}{llllllllllllllllllllllll}C . E & 0 & 3 & 7 & 10 & 11 & 13 & 14 & 10 & 17 & 19 & 20 & 20 & 20 & 21 & 21 & 21 & 21 & 29 & 22 & 22 & 22 \\ \text { N.R } & 37 & 33 & 29 & 25 & 22 & 19 & 17 & 15 & 12 & 10 & 8 & 7 & 6 & 4 & 4 & 4 & 4 & 4 & 2 & 2 & 2\end{array}$

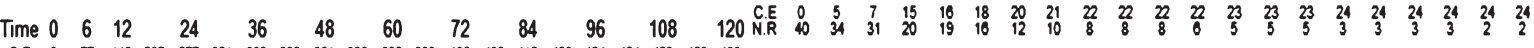

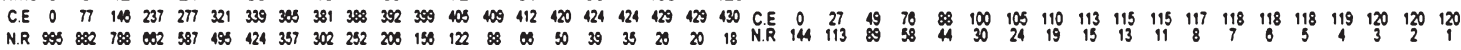

Fig. 2. Kaplan-Meier survival analysis assessing (A) overall mortality -free rates in 995 bladder cancer patients treated with radical cystoprostatectomy. Analyses were repeated (B) after stratifying patients according to the level of prostatic invasion (no invasion vs. prostatic urethral CIS vs. lamina propria invasion vs. ductal CIS vs. stromal invasion). 
Table 4

Univariable and multivariable Cox regression analyses predicting overall mortality in 995 male patients treated with radical cystoprostatectomy for bladder cancer

\begin{tabular}{|c|c|c|c|c|}
\hline \multirow[t]{2}{*}{ Variables } & \multicolumn{2}{|c|}{ Univariable analyses } & \multicolumn{2}{|c|}{ Multivariable analyses } \\
\hline & HR (CI 95\%) & $\overline{p \text { value }}$ & HR (CI 95\%) & $p$ value \\
\hline Age, years & $1.03(1.02-1.04)$ & $<0.001$ & $1.02(1.01-1.03)$ & $<0.001$ \\
\hline \multicolumn{5}{|l|}{ Histological types } \\
\hline Urothelial pure & Ref & Ref & Ref & Ref \\
\hline Variant & $1.64(1.23-2.17)$ & 0.001 & $1.36(1.02-1.82)$ & 0.04 \\
\hline \multicolumn{5}{|l|}{ Pathologic T stage } \\
\hline pT0-T1 & Ref & Ref & Ref & Ref \\
\hline pT2 & $2.40(1.78-3.25)$ & $<0.001$ & $1.58(1.13-2.21)$ & 0.008 \\
\hline pT3 & $4.72(3.65-6.11)$ & $<0.001$ & $2.00(1.43-2.79)$ & $<0.001$ \\
\hline pT4 & $7.30(5.30-10.05)$ & $<0.001$ & $2.00(1.31-3.03)$ & 0.001 \\
\hline \multicolumn{5}{|c|}{ 年 } \\
\hline No prostatic involvement & Ref & Ref & Ref & Ref \\
\hline Prostatic Urethra/CIS & $1.86(1.33-2.59)$ & $<0.001$ & $1.53(1.09-2.16)$ & 0.01 \\
\hline Ductal CIS & $1.86(1.21-2.86)$ & 0.005 & $1.66(1.06-2.60)$ & 0.03 \\
\hline Lamina propria invasion & $2.05(1.34-3.14)$ & 0.001 & $1.82(1.80-2.81)$ & 0.007 \\
\hline Stromal invasion & $4.40(3.51-5.50)$ & $<0.001$ & $1.96(1.49-2.59)$ & $<0.001$ \\
\hline Lymphovascular invasion & $3.93(3.21-4.81)$ & $<0.001$ & $1.91(1.45-2.51)$ & $<0.001$ \\
\hline Lymph node invasion & $3.29(2.71-3.99)$ & $<0.001$ & $1.44(1.13-1.83)$ & 0.003 \\
\hline STSM & $1.26(0.85-1.86)$ & 0.2 & $1.37(0.89-2.10)$ & 0.1 \\
\hline Adjuvant chemotherapy & $1.03(0.81-1.31)$ & 0.8 & $0.87(0.66-1.13)$ & 0.3 \\
\hline
\end{tabular}

These results highlight the importance of a carefully description of UPI in prostate specimens after radical cystoprostatectomy. We confirm that whole mount sections detected higher incidence of UPI as previously described [27, 28].

Ayyathurai et al. [7] investigated prostatic involvement with conventional pathologic processing. They found a rate of prostatic involvement of $24 \%$ compared to $30,9 \%$ found in our series. These results confirm previous literature supporting the role of whole mount prostate evaluation in radical cystoprostatectomy patients [29]. However, different pathologic evaluation is only one of the parameters that might have change between the two series and therefore prospective data are required to analyze the impact of different pathologic evaluation on UPI diagnoses after radical cystoprostatectomy.

Despite several strengths, our study is not devoid of limitations. Firstly, we recognize that our study is limited by its observational and retrospective nature, and thus our results should be interpreted with caution. Second, no central pathologic review has been performed and every center involved analyzed the studied specimen independently. On the other hand, all the centers involved in the study were institutional centers with dedicated uropathologists. Third, the lack of some potentially important confounders (urinary diversion type and number of nodes removed) partially limits our findings. Fourth, no data regarding recurrence or cancer specific mortality was available for this cohort. Fifth, in the present cohort we were unable to evaluate the percentage of variant histology in bladder cancer specimen after radical cystoprostatectomy that is potentially related to the survival outcomes. Moreover, it has to be report that all the patients diagnosed with non-urothelial disease were grouped together. Sixth, levels of UPI were decided arbitrarily and might not represent the best categorization for the prediction of survival outcomes. Specifically, we were not able to differentiate different pattern of stromal invasion, from the bladder wall or from prostatic urethra that might have a different impact on survival outcomes.

\section{CONCLUSION}

In conclusion, we confirm prior studies demonstrating that prostatic urethra involvement with bladder cancer at the time of radical cystoprostatectomy represents an important poor prognostic indicator. In this setting, we demonstrated that different levels of involvement are associated with different survival expectancies. Finally, we found that several preoperative and pathological factors can be successfully used by physicians to predict this adverse pathological feature.

\section{ACKNOWLEDGMENTS}

Marco Moschini is supported by the EUSP Scholarship - European Association of Urology. 


\section{ETHICAL STANDARDS}

All person gave their informed consent to use their data for this retrospective study.

\section{CONFLICT OF INTEREST}

The authors declare that they have no conflict of interest.

\section{REFERENCES}

[1] Witjes JA, Compérat E, Cowan NC, De Santis M, Gakis $\mathrm{G}$, Lebret $\mathrm{T}$, et al. EAU guidelines on muscleinvasive and metastatic bladder cancer: summary of the 2013 guidelines. Eur Urol [Internet] 2014 [cited 2014 Aug 25];65(4):778-92. Available from: http://www.ncbi. nlm.nih.gov/pubmed/24373477

[2] Moschini M, Karnes RJ, Sharma V, Gandaglia G, Fossati $\mathrm{N}$, Dell'Oglio P, et al. Patterns and prognostic significance of clinical recurrences after radical cystectomy for bladder cancer: A 20-year single center experience. Eur J Surg Oncol [Internet] 2016 [cited 2016 Mar 29]; Available from: http://www.ncbi.nlm.nih.gov/pubmed/ 26927300

[3] Colombo R, Pellucchi F, Moschini M, Gallina A, Bertini $\mathrm{R}$, Salonia A, et al. Fifteen-year single-centre experience with three different surgical procedures of nerve-sparing cystectomy in selected organ-confined bladder cancer patients. World J Urol [Internet] 2015; Available from: http://www.ncbi.nlm.nih.gov/pubmed/25577131

[4] Walsh PC, Schlegel PN. Radical pelvic surgery with preservation of sexual function. Ann Surg [Internet] 1988 [cited 2014 Aug 25];208(4):391-400. Available from: http://www.pubmedcentral.nih.gov/articlerender.fcgi?artid $=1493736 \&$ tool $=$ pmcentrez\&rendertype $=$ abstract

[5] Colombo R, Bertini R, Salonia A, Naspro R, Ghezzi M, Mazzoccoli B, et al. Overall clinical outcomes after nerve and seminal sparing radical cystectomy for the treatment of organ confined bladder cancer. J Urol [Internet] 2004 [cited 2014 Aug 25];171(5):1819-22; discussion 1822. Available from: http://www.ncbi.nlm.nih.gov/pubmed/15076284

[6] Ong CH, Schmitt M, Thalmann GN, Studer UE. Individualized seminal vesicle sparing cystoprostatectomy combined with ileal orthotopic bladder substitution achieves good functional results. J Urol [Internet] 2010 [cited 2014 Aug 25];183(4):1337-41. Available from: http://www.ncbi.nlm.nih.gov/pubmed/20171690

[7] Ayyathurai R, Gomez P, Luongo T, Soloway MS, Manoharan M. Prostatic involvement by urothelial carcinoma of the bladder: Clinicopathological features and outcome after radical cystectomy. BJU Int [Internet] 2007;100(5):1021-5. Available from: http://www.ncbi. nlm.nih.gov/pubmed/17784885

[8] Knoedler JJ, Boorjian SA, Tollefson MK, Cheville JC, Thapa P, Tarrell RF, et al. Urothelial carcinoma involving the prostate: The association of revised tumour stage and coexistent bladder cancer with survival after radical cystectomy. BJU Int 2014;114(6):832-6.

[9] Moschini M, Luzzago S, Zaffuto E, Dell'Oglio P, Gandaglia $\mathrm{G}$, Mattei A, et al. The surgical management of patients with clinical stage T4 bladder cancer: A single institution experience. Eur J Surg Oncol [Internet] 2016; Available from: http://www.ncbi.nlm.nih.gov/pubmed/27720312

[10] Aziz A, Shariat SF, Roghmann F, Brookman-May S, Stief CG, Rink M, et al. Prediction of cancer-specific survival after radical cystectomy in pT4a urothelial carcinoma of the bladder: Development of a tool for clinical decision-making. BJU Int 2016;117(2):272-9.

[11] Ploussard G, Rotondo S, Salomon L. The prognostic significance of bladder neck invasion in prostate cancer: Is microscopic involvement truly a T4 disease? BJU Int [Internet] 2010;105(6):776-81. Available from: http://doi.wiley.com/10.1111/j.1464-410X.2009.08957.x

[12] Liberman D, Alasker A, Sun M, Ismail S, Lughezzani G, Jeldres C, et al. Radical cystectomy for patients with pT4 urothelial carcinoma in a large population-based study. BJU Int 2011;107:905-11.

[13] Nagele U, Anastasiadis AG, Merseburger AS, Corvin $\mathrm{S}$, Hennenlotter $\mathrm{J}$, Adam $\mathrm{M}$, et al. The rationale for radical cystectomy as primary therapy for T4 bladder cancer. World J Urol [Internet] 2007 [cited 2014 Aug 25];25(4):401-5. Available from: http://www.ncbi.nlm. nih.gov/pubmed/17525849

[14] May M, Brookman-May S, Burger M, Gilfrich C, Fritsche H-M, Rink M, et al. Concomitant seminal vesicle invasion in pT4a urothelial carcinoma of the bladder with contiguous prostatic infiltration is an adverse prognosticator for cancerspecific survival after radical cystectomy. Ann Surg Oncol 2014;21(12):4034-40.

[15] Shariat SF, Svatek RS, Tilki D, Skinner E, Karakiewicz PI, Capitanio U, et al. International validation of the prognostic value of lymphovascular invasion in patients treated with radical cystectomy. BJU Int [Internet] 2010;105(10):1402-12. Available from: http://www.ncbi. nlm.nih.gov/pubmed/20132195

[16] Rink M, Fajkovic H, Cha EK, Gupta A, Karakiewicz PI, Chun FK, et al. Death certificates are valid for the determination of cause of death in patients with upper and lower tract urothelial carcinoma. Eur Urol [Internet] 2012 [cited $2016 \mathrm{Feb} 25$ ];61(4):854-5. Available from: http://www.ncbi.nlm.nih.gov/pubmed/22226583

[17] Bruins HM, Djaladat H, Ahmadi H, Sherrod A, Cai J, Miranda G, et al. Incidental prostate cancer in patients with bladder urothelial carcinoma: Comprehensive analysis of 1,476 radical cystoprostatectomy specimens. J Urol [Internet] 2013;190(5):1704-9. Available from: http:// linkinghub.elsevier.com/retrieve/pii/S0022534713043747

[18] Pignot G, Salomon L, Lebacle C, Neuzillet Y, Lunardi $\mathrm{P}$, Rischmann $\mathrm{P}$, et al. Prostate cancer incidence on cystoprostatectomy specimens is directly linked to age: Results from a multicentre study. BJU Int [Internet] 2015;115(1):87-93. Available from: http://doi.wiley.com/ 10.1111/bju. 12803

[19] Yang X, Monn MF, Liu L, Liu Y, Su J, Lyu T, et al. Incidental prostate cancer in Asian men: High prevalence of incidental prostatic adenocarcinoma in Chinese patients undergoing radical cystoprostatectomy for treatment of bladder cancer and selection of candidates for prostatesparing cystectomy. Prostate [Internet] 2015;75(8):845-54. Available from: http://doi.wiley.com/10.1002/pros.22966

[20] Pignot G, Salomon L, Neuzillet Y, Masson-Lecomte A, Lebacle C, Patard J-J, et al. Clinicopathological characteristics of incidental prostate cancer discovered from radical cystoprostatectomy specimen: A multicenter french study. Ann Surg Oncol [Internet] 2014;21(2):684-90. Available from: http://link.springer.com/10.1245/s10434-013-3340-8 
[21] Barbisan F, Mazzucchelli R, Scarpelli M, Lopez-Beltran A, Cheng L, Kirkali Z, et al. Urothelial and incidental prostate carcinoma in prostates from cystoprostatectomies for bladder cancer: Is there a relationship between urothelial and prostate cancer? BJU Int [Internet] 2009;103(8):105863. Available from: http://doi.wiley.com/10.1111/j.1464410X.2008.08207.x

[22] Pan J, Xue W, Sha J, Yang H, Xu F, Xuan H, et al. Incidental prostate cancer at the time of cystectomy: The incidence and clinicopathological features in Chinese patients. PLoS One [Internet] 2014;9(4):e94490. Available from: http://www.ncbi.nlm.nih.gov/pubmed/24722643

[23] Damiano R, Di Lorenzo G, Cantiello F, De Sio M, Perdonà $\mathrm{S}$, D'Armiento $\mathrm{M}$, et al. Clinicopathologic features of prostate adenocarcinoma incidentally discovered at the time of radical cystectomy: An evidence-based analysis. Eur Urol [Internet] 2007;52(3):648-57. Available from: http://www.ncbi.nlm.nih.gov/pubmed/17600614

[24] Montironi R, Cheng L, Mazzucchelli R, Scarpelli M, Kirkali $\mathrm{Z}$, Montorsi $\mathrm{F}$, et al. Critical evaluation of the prostate from cystoprostatectomies for bladder cancer: Insights from a complete sampling with the whole mount technique. Eur Urol [Internet] 2009;55(6):1305-9. Available from: http://www.ncbi.nlm.nih.gov/pubmed/18995951

[25] Mazzucchelli R, Barbisan F, Santinelli A, Scarpelli M, Galosi AB, Lopez-Beltran A, et al. Prediction of prostatic involvement by urothelial carcinoma in radical cystoprostatectomy for bladder cancer. Urology [Internet]
2009 [cited 2016 Feb 15];74(2):385-90. Available from: http://www.ncbi.nlm.nih.gov/pubmed/19501882

[26] Tabibi A, Simforoosh N, Parvin M, Abadpour B, Abdi $\mathrm{H}$, Khafri S. Prediction of prostatic involvement by transitional cell carcinoma of the bladder using pathologic characteristics of the bladder tumor. Urol $\mathbf{J}$ [Internet]. 2006 [cited 2016 Feb 15];3(3):145-9. Available from: http://www.ncbi.nlm.nih.gov/pubmed/17559030

[27] Revelo MP, Cookson MS, Chang SS, Shook MF, Smith JA, Shappell SB. Incidence and location of prostate and urothelial carcinoma in prostates from cystoprostatectomies: Implications for possible apical sparing surgery. J Urol [Internet] 2004;171(2 Pt 1):646-51. Available from: http://www.ncbi.nlm.nih.gov/pubmed/14713778

[28] Shen SS, Lerner SP, Muezzinoglu B, Truong LD, Amiel G, Wheeler TM. Prostatic involvement by transitional cell carcinoma in patients with bladder cancer and its prognostic significance. Hum Pathol [Internet] 2006;37(6):72634. Available from: http://www.ncbi.nlm.nih.gov/pubmed/ 16733214

[29] Montironi R, Lopez Beltran A, Mazzucchelli R, Cheng L, Scarpelli M. Handling of radical prostatectomy specimens: Total embedding with large-format histology. Int J Breast Cancer [Internet] 2012;2012:932784. Available from: http://www.ncbi.nlm.nih.gov/pubmed/22844601 